\title{
Infrared photo-induced force microscopy unveils nanoscale features of Norway spruce fibre wall
}

\author{
Kavindra Kumar Kesari (D) P Padraic O'Reilly • Jani Seitsonen • \\ Janne Ruokolainen · Tapani Vuorinen
}

Received: 5 March 2021 / Accepted: 10 June 2021 / Published online: 16 June 2021

(C) The Author(s) 2021

\begin{abstract}
Infrared photo-induced force microscopy (IR PiFM) was applied for imaging ultrathin sections of Norway spruce (Picea abies) at $800-1885 \mathrm{~cm}^{-1}$ with varying scanning steps from 0.6 to $30 \mathrm{~nm}$. Cell wall sublayers were visualized in the low-resolution mode based on differences in their chemical composition. The spectra from the individual sublayers demonstrated differences in the orientation of cellulose elementary fibrils (EFs) and in the content and structure of lignin. The high-resolution images revealed 5-20 nm wide lignin-free areas in the $S_{1}$ layer. Full spectra collected from a non-lignified spot and at a short distance apart from it verified an abrupt
\end{abstract}

Supplementary Information The online version contains supplementary material available at https://doi.org/10.1007/ s10570-021-04006-2.

K. K. Kesari $(\bowtie) \cdot J$. Seitsonen · J. Ruokolainen $(\bowtie)$

Department of Applied Physics, School of Science, Aalto University, 00076 Espoo, Finland

e-mail: kavindra.kesari@aalto.fi

J. Ruokolainen

e-mail: janne.ruokolainen@aalto.fi

K. K. Kesari · T. Vuorinen ( $₫)$

Department of Bioproducts and Biosystems, School of Chemical Engineering, Aalto University, 00076 Espoo,

Finland

e-mail: tapani.vuorinen@aalto.fi

P. O'Reilly

Molecular Vista, San Jose, CA 95119, USA change in the lignin content and the presence of tangentially oriented EFs. Line scans across the ligninfree areas corresponded to a spatial resolution of $\leq 5$ $\mathrm{nm}$. The ability of IR PiFM to resolve structures based on their chemical composition differentiates it from transmission electron microscopy that can reach a similar spatial resolution in imaging ultrathin wood sections. In comparison with Raman imaging, IR PiFM can acquire chemical images with $\geq 50$ times higher spatial resolution. IR PiFM is also a surfacesensitive technique that is important for reaching the high spatial resolution in anisotropic samples like the cell wall. All these features make IR PiFM a highly promising technique for analyzing the recalcitrant nature of lignocellulosic biomass for its conversion into various materials and chemicals. 


\section{Graphic abstract}

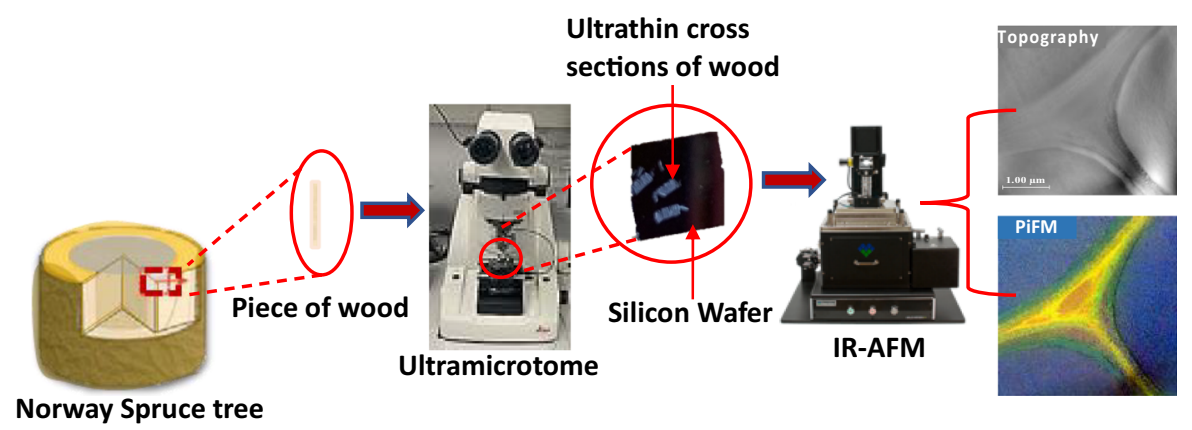

Keywords Cellulose elementary fibril $\cdot$ Chemical imaging · Infrared spectroscopy · Lignin · Photoinduced force microscopy $\cdot$ Plant cell wall $\cdot$ Spruce wood

\section{Introduction}

Replacing fossil carbon sources with biomass as a source of materials and chemicals sets increasing needs for understanding the structure of biomass on molecular to nanostructural scales. This knowledge is required in developing more efficient ways of fractionating and processing plant fibers and their constituents (Charrier et al. 2018; Sorieul et al. 2016). The complex architecture of lignified wood fibers includes several secondary cell wall layers $\left(\mathrm{S}_{1}, \mathrm{~S}_{2}, \mathrm{~S}_{3}\right)$ along with their transition layers $\left(S_{1-2}, S_{2-3}\right)$, compound middle lamella (CML), and cell corner middle lamella (CCML). Scanning electron microscopy (SEM) and transmission electron microscopy (TEM), especially have provided detailed information on the organization of cellulose elementary fibrils (EFs) in the sublayers of wood cell walls (CW). TEM tomography has been applied to visualize EF assemblies in 3D (Reza et al. 2014a, b; Reza et al. 2019). In general, the thick $S_{2}$ layer of normal wood fibers consists of close to axially oriented EFs that may aggregate to form (micro) fibrils or lamellae (Abe et al. 1991; Donaldson 2008). In thin $S_{1}$ and $S_{3}$ layers, the fibril angle, i.e. the angle between the fiber and EF axes, is much larger (Plaza et al. 2016; Wiedenhoeft 2013). In the thin $S_{1-2}$ layer, the ends of EFs with distinctly different fibril angles cross which results in an abnormally high cellulose content in this layer (Reza et al. 2019). Many researchers have reported the occurrence of EFs in $S_{1}$, $S_{2}$, and $S_{3}$ layers, where $S_{1}, S_{3}$ has transversely oriented and $S_{2}$ has axially oriented EFs (Abe et al. 1992; Abe and Funada 2005; Brändström et al. 2003; Donaldson 2008; Donaldson and Xu 2005; Maaß et al. 2020; Huang et al. 2003).

In secondary cell wall, EFs or their aggregates are surrounded by a matrix of hemicelluloses and lignin (Chundawat et al. 2011). The softwood hemicelluloses of normal wood consist mostly of O-acetylated galactoglucomannan and arabino-4-O-methylglucuronoxylan (Ibn et al. 2017; Lyczakowski et al. 2019; Stevanic 2011). In contrast, complex pectins are the main polysaccharides of the CML and CCML regions (Melelli et al. 2020). Galacturonans and rhamnogalacturonans are major substructures of the pectins where the galacturonic acid units are partially methylated (esterified) (Bonnin et al. 2014). The softwood lignin is of the guaiacyl type, formed mostly through oxidative polymerization of coniferyl alcohol (Jingjing 2011). The lignin content of wood is highest in CCML and CML (Zhang et al. 2020). In these regions, the lignin is more condensed or cross-linked in comparison with the secondary wall lignin. Dibenzodioxocin structures are typical of cross-linked guaiacyl lignin (Bock et al. 2020; Kukkola et al. 2003). Softwood lignin may also contain ring-conjugated structures, such as coniferyl alcohol and aldehyde units and $\alpha$-carbonyl groups (Johansson 2000; Lin and Kringstad 1970a, b).

Analyzing the chemical structure of specific regions of $\mathrm{CW}$ is a challenging task. Distribution of 
lignin in microtome sections of wood has been studied by TEM, UV and visible light microscopy and Raman microscopy (Kesari et al. 2020; Reza et al. 2014a, b; Reza et al. 2019). Achieving contrast with TEM requires specific staining e.g. with permanganate or use of immunolabeling techniques (Reza et al. 2014a, b; Reza et al. 2015). While UV microscopy is specific for lignin Raman imaging can provide information on both lignin and cell wall polysaccharides (Kesari et al. 2020; Reza et al. 2014b; Dou et al. 2018). Thus, Raman microscopy has provided information e.g. on orientation of EFs and distribution of ring conjugated lignin monomers in $\mathrm{CW}$ (Gierlinger and Schwanninger, 2006; Gierlinger et al. 2010; Hänninen et al. 2011). However, the diffraction limited spatial resolution of optical Raman microscopy is insufficient for observing the detailed structure of $\mathrm{CW}$. Although the orientation of cell wall polymers has been studied by Fourier transform infrared (FITR) microscopy (Stevanic and Salmen 2009), the low resolution of the technique does not allow studying individual cell wall sublayers.

In recent years, a number of highly advanced techniques like tip-enhanced Raman spectroscopy (TERS), infrared atomic force microscopy (AFMIR), and infrared photo-induced force microscopy (IR PiFM), especially, have provided spectroscopic imaging with nano-scale spatial resolution (Levin and Bhargava 2005; Lewis et al. 1995; Nguyen et al. 2020; Ogunleke et al. 2017; Xiao and Schultz 2018). AFMIR based on thermal expansion of the material has been applied for studying wood cell wall (Wang et al. 2016; Gusenbauer et al. 2020) and xylem pit membranes (Pereira et al. 2018). Gusenbauer et al. (2020) reported a spatial resolution of $16 \mathrm{~nm}$ in their measurements. IR PiFM is a multimodal technique that combines FM with tunable IR laser excitation to obtain nondestructive chemical information with $<$ $10 \mathrm{~nm}$ resolution via near-field imaging (Nowak et al. 2016). The high spatial resolution of the technique is based on measuring the short-range force between the polarized sample and its mirror image on the tip. IR PiFM spectra correlate well with the bulk FTIR spectra of homogenous samples. On samples with nanoscale heterogeneity, PiFM spectra yield local IR absorption information from $\sim 10 \mathrm{~nm}$ region underneath the tip. Hyperspectral mapping is a mode of PiFM that enables hyperspectral nanochemical mapping (Murdick et al. 2017).
In the present study we applied IR PiFM for studying ultrathin microtome sections of Norway spruce (Picea abies) wood with an aim of getting direct spectroscopic data on the cell wall polymers and their organization in the sublayers of $\mathrm{CW}$ (Fig. 1). Earlier we studied the wood from the same tree by TEM and TEM tomography of permanganate stained microtome sections. From these studies we got detailed information on orientation and organization of EFs in CW. With TEM tomography, we were able to visualize the occurrence of helical EF bundles in the $S_{1}$ layer and entangling of $E F$ ends in the $S_{1-2}$ transition layer (Reza et al. 2017, 2019).

\section{Material and methods}

Materials and sample preparation

A piece of ca. 15 years old Norway spruce (Picea abies) was collected at breast height $(1.3 \mathrm{~m})$ in Espoo, Southern Finland. The piece of wood was cut into cubes $\left(3 \times 5 \times 10 \mathrm{~mm}^{3}\right)$ and directly transferred inside the cryo-chamber $\left(-65^{\circ} \mathrm{C}\right)$ of a Leica EM FC7 ultramicrotome. Ultrathin cross (transverse) sections $(150 \mathrm{~nm})$ were cut from the cubes with a diamond knife (Cryo $35^{\circ}$ of DiATOME, Switzerland). The sections were collected on silicon wafers with the help of an eyelash mounted on a pole (Reza et al. 2014a, b; Reza et al. 2019). The region that was imaged was latewood in the fifth annual ring from the pith.

Photo-induced force microscopy (PiFM) and hyperspectral PiFM IR (hyPIR) imaging

All PiFM and hyPIR measurements were carried out using a VistaScope microscope from Molecular Vista Inc. (San Jose, CA, USA), coupled with Block Engineering's (Southborough, MA, USA) LaserTune QCL tunable mid-IR quantum cascade laser, with a wavenumber range of $775-1885 \mathrm{~cm}^{-1}$ and a spectral line width of $2 \mathrm{~cm}^{-1}$. The QCL laser beam was focused by a parabolic mirror at the interface between the sample and the AFM tip in an elliptical spot size of approximately $\lambda \times 1.5 \lambda$. The average laser power on the sample surface was $0.1 \mathrm{~mW}$ during the imaging. The angle and direction of the laser beam on the sample is indicated in Fig. 2. AFM was operated in 


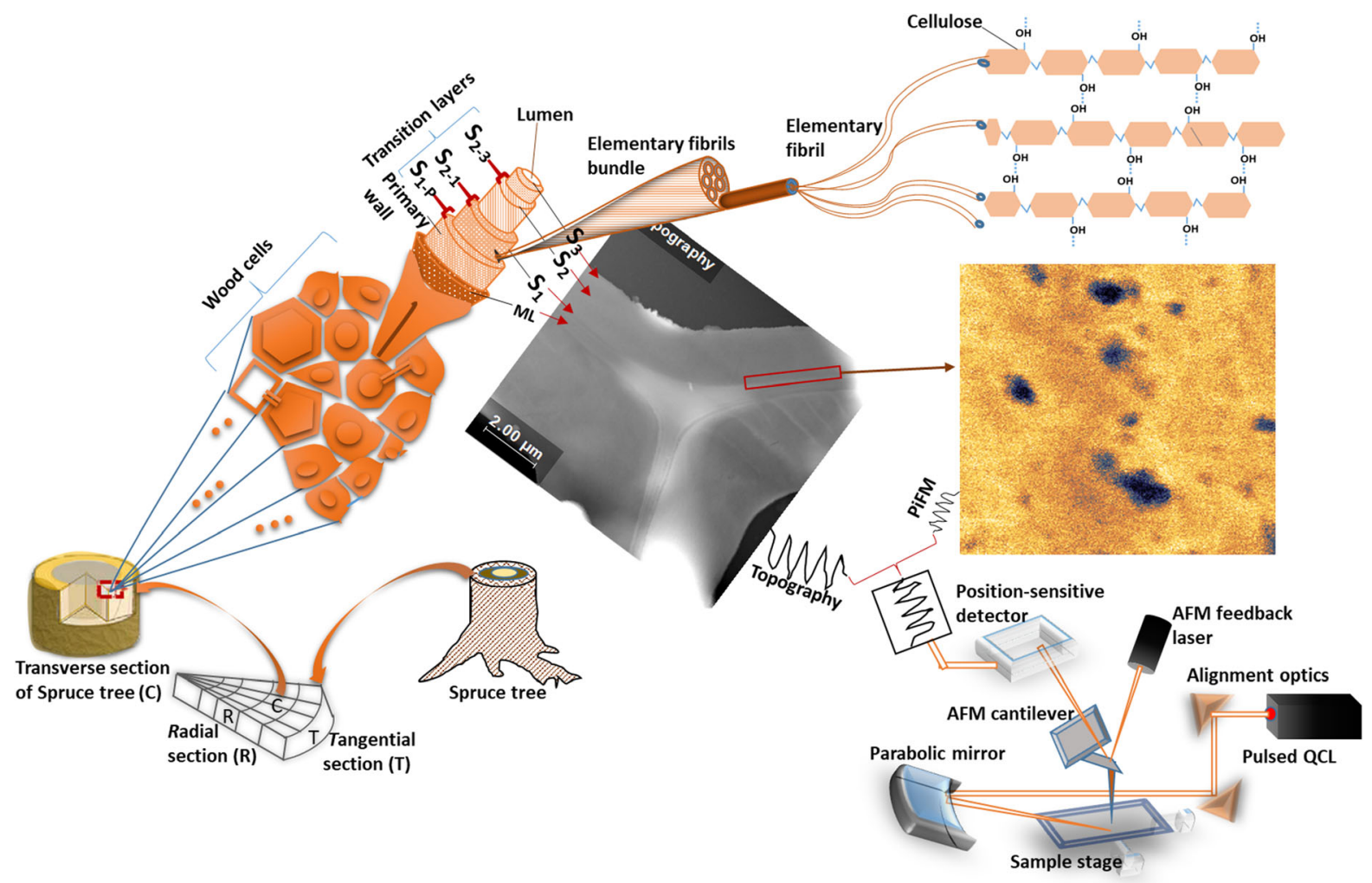

Fig. 1 IR PiFM experiment includes sectioning of the wood, selection of an area of interest, topography and PiFM imaging (partially adopted from Reza et al. 2019). The functioning of AFM feedback system and the feedback laser position-sensitive detector record the topography of the sample and lock-in electronics concurrently record the PiFM images at variable
QCL laser frequencies. Mechanism of detection in more detailed has been discussed elsewere (Nowak et al. 2016). Topography shows, in part, $\mathrm{CW}$ layering $\left(\mathrm{CML}, \mathrm{S}_{1}, \mathrm{~S}_{1-2}, \mathrm{~S}_{2}, \mathrm{~S}_{2-}\right.$ ${ }_{3}, S_{3}$ ). In contrast, IR PiFM images show details of the layers such as small lignin-free spots in $\mathrm{S}_{1}$ on underlying EFs
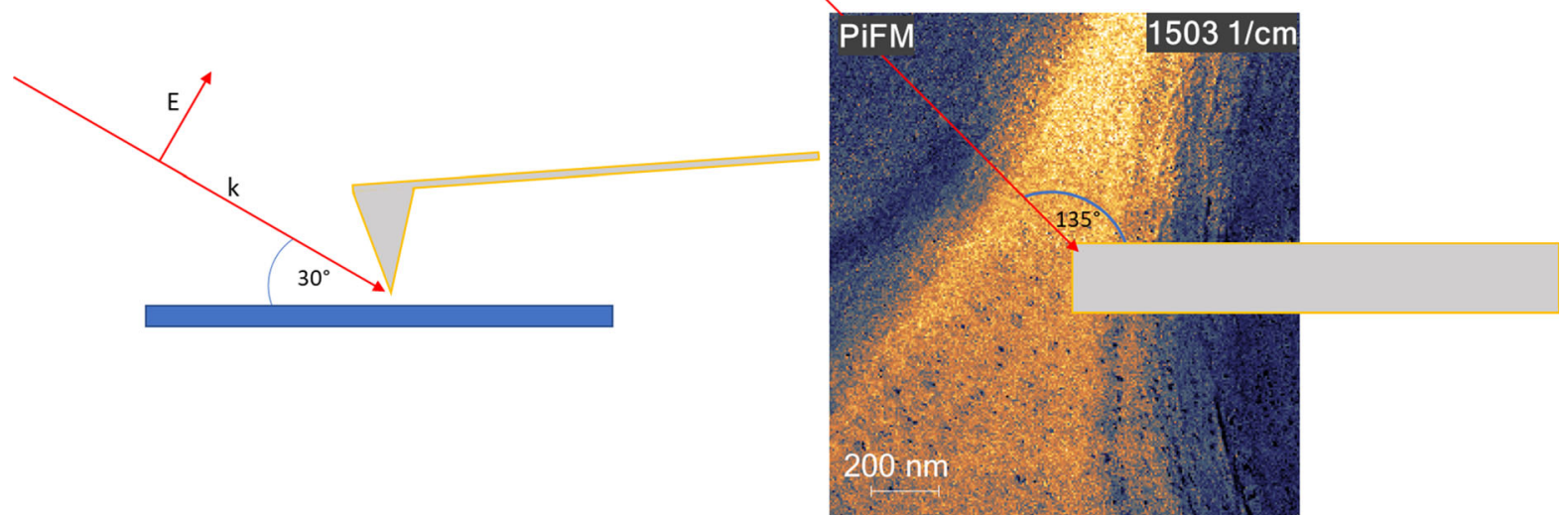

Fig. 2 Schematic presentation on the QCL laser beam (k) direction relative to the cantilever and the sample. The PiFM image shows part of radial wall close to cell corner. The direction of the electric field $(\mathrm{E})$ of the linearly polarized laser

beam is also shown. The angle shows the direction of the laser to the tip, where laser coming in at an angle of $30^{\circ}$ from the surface of the sample and $\sim 135^{\circ}$ from the cantilever axis 
dynamic non-contact mode and gold-coated $\mathrm{NCH}$ $300 \mathrm{kHz}$ cantilevers from Nanosensors (Neuchatel, Switzerland) were used for all measurements.

The modulation frequency of the QCL laser, $\omega_{\mathrm{m}}$, was selected so that $\omega_{\mathrm{m}}=\omega_{1}-\omega_{0}$, where $\omega_{0}$ and $\omega_{1}$ are the 1 st and 2 nd mechanical resonance modes of the cantilever, this was referred to as the sideband mode and takes advantage of the quality factor of the cantilever to increase sensitivity (Nowak et al. 2016). In the default setup, topography was recorded on the 2nd mode, while PiFM was detected on the 1st.

The size of all topography, PiFM (response at specific spectral lines) and hyPIR (full spectrum at each pixel) images was $256 \times 256$ pixels. All image and data processing were carried out using SurfaceWorks. The scan size for a low resolution hyPIR image was $7.66 \times 7.66 \mu \mathrm{m}^{2}(30 \mathrm{~nm}$ step between pixels) while the spectrum acquisition time at each pixel was $200 \mathrm{~ms}$ over a range of $800-1885 \mathrm{~cm}^{-1}$. The hyPIR spectra were divided by the wavenumber dependent laser power intensity profile for normalization. Using SurfaceWorks, average spectra were determined on various regions of interest, (CCML, CML, $\mathrm{S}_{1}, \mathrm{~S}_{2}, \mathrm{~S}_{3}$, CML and CCML and their transition layers CML- $S_{1}, S_{1-2}$ and $S_{2-3}$ ). The advantage of this AFM-based technique is that if there is any damage, any rescan or scan of a larger area will reveal the damage. Therefore, no damages were observed with PiFM and other measurements.

Medium resolution PiFM images of $4 \times 4 \mu^{2}$ (15.6 nm steps) and $1.0 \times 1.0 \mu \mathrm{m}^{2}(3.9 \mathrm{~nm}$ steps $)$ were collected at 1057, 1267, 1503, 1650 and $1744 \mathrm{~cm}^{-1}$ using a scan speed of 0.19 line/s. High resolution PiFM images of $400 \times 400 \mathrm{~nm}^{2}(1.6 \mathrm{~nm}$ steps $)$ and $150 \times 150 \mathrm{~nm}^{2}(0.6 \mathrm{~nm}$ steps $)$ were collected at 1051,1504 and $1740 \mathrm{~cm}^{-1}$ with a scan speed of 0.89 line/s. Point PiFM spectra with acquisition time of $30 \mathrm{~s}$ over a range of $800-1885 \mathrm{~cm}^{-1}$ were collected separately from different locations of interest.

\section{Results and discussion}

hyperspectral PiFM IR (hyPIR) images of cell wall and PiFM spectra of its sublayers

Topography and hyPIR images of the whole cell wall were obtained first in a low resolution $(30 \mathrm{~nm})$
(Fig. 3). The topography image was most similar to the hyPIR image at $1166 \mathrm{~cm}^{-1}$. This absorption band is specific for cellulose chains that are parallel with the plane of polarization of the linearly polarized light of the used QCL laser source (Stevanic and Salmen 2009). In normal wood, cellulose elementary fibrils (EFs) are aligned close to axially only in the $S_{2}$ layer (Reza et al. 2019). Therefore, the topography image and the hyPIR image at $1166 \mathrm{~cm}^{-1}$ differentiate $S_{2}$ from the rest of the cell wall. The hyPIR images at 1505,1471 and $1220 \mathrm{~cm}^{-1}$ had similar high intensity profiles in the CCML and narrow CML regions (Fig. 3). All these absorption bands are characteristic for lignin and indicative of high lignin content in CCML and CML (Bock et al. 2020; Larsen and Barsberg 2010). A similar, although weaker, intensity profile was observed in the hyPIR image at $1145 \mathrm{~cm}^{-1}$, indicating that also this band originated from lignin (Bock et al. 2020).

The hyPIR images at 1034, 1060 and $1096 \mathrm{~cm}^{-1}$ gave an impression on two additional sublayers between CML/CCML and $\mathrm{S}_{2}$ (Fig. 3). These layers were tentatively assigned as $S_{1}$ and $S_{1-2}$. The reportedly high cellulose content in the $S_{1-2}$ transition layer, where the ends of EFs of $S_{1}$ and $S_{2}$ cross, could explain the high absorption intensity in this region although lignin has some overlapping absorption. The hypIR image at $1733 \mathrm{~cm}^{-1}$ showed similarly the presence of the sublayers even though this absorption may originate from ester groups in both acetylated galactoglucomannans and methyl esterified pectins (Schulz and Baranska 2007; Stefke et al. 2008). Based on the topography and hyPIR images, the overall thickness of the region $S_{1-2}-S_{1}-C M L-S_{1}-S_{1-2}$ was $700-800 \mathrm{~nm}$, of which CML formed 100-200 nm. Although the resolution $(30 \mathrm{~nm})$ was too low to determine the thicknesses precisely, the values are in the range reported earlier.

Because the acquisition time for each spectrum in the hyPIR image was only $200 \mathrm{~ms}$, the signal-to-noise ratio of individual spectra was low. Therefore, average spectra were calculated for regions representing different sublayers of the cell wall (Fig. 4, Supplementary Figs. 1 and 2). The $S_{2}$ layer was homogeneous throughout its thickness $(3.5 \mu \mathrm{m})$ and the parallel polarization specific cellulose band at $1166 \mathrm{~cm}^{-1}$ was the most characteristic feature of the spectra. Additionally, strong absorption maxima present at 1034 and $1060 \mathrm{~cm}^{-1}$ besides a weaker one at 

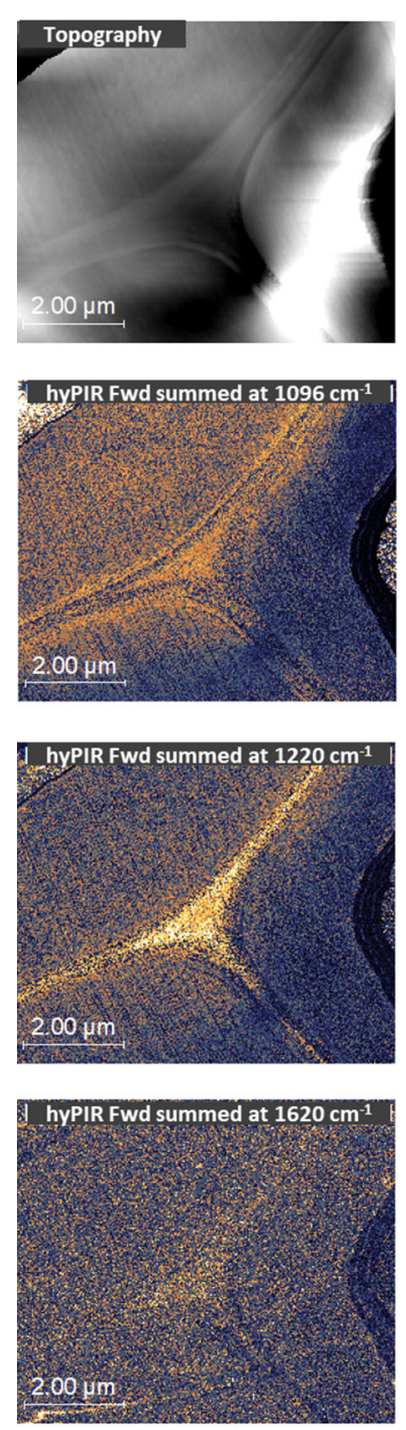
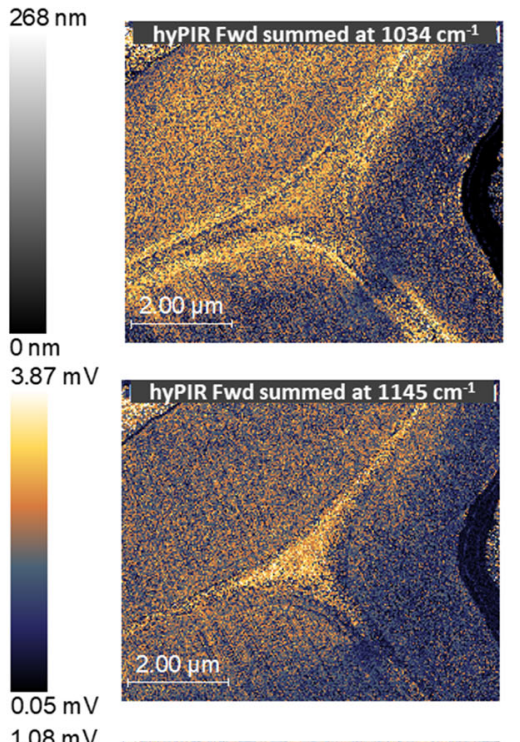

$1.08 \mathrm{mV}$
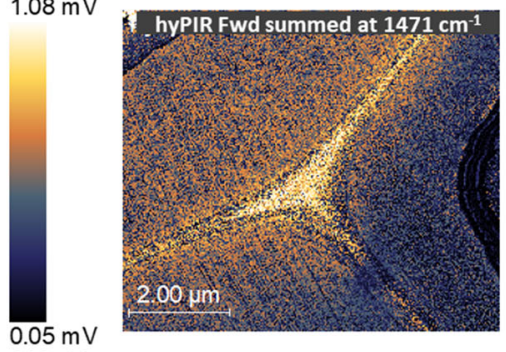

$444 \mu \mathrm{V}$
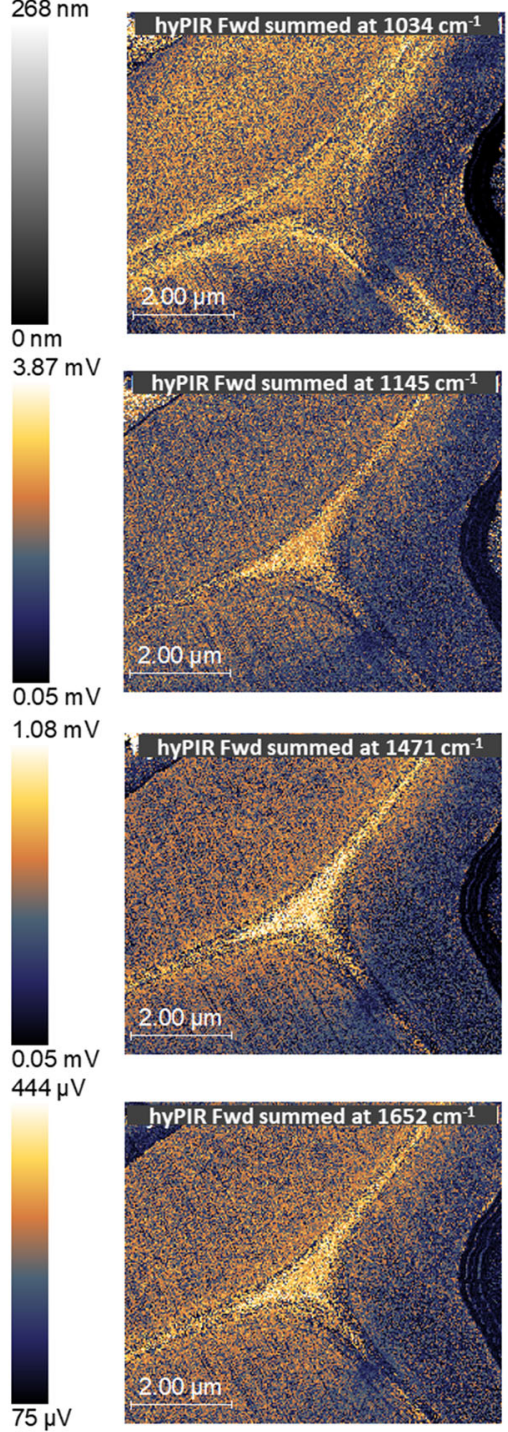
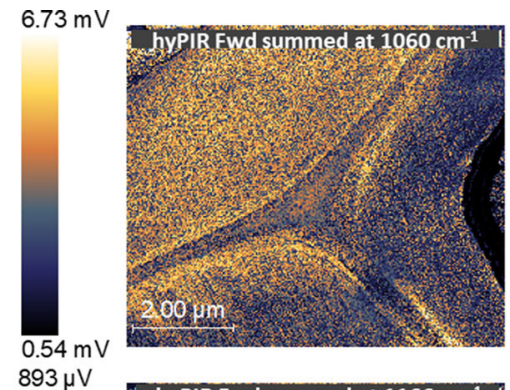

$893 \mu \mathrm{V}$

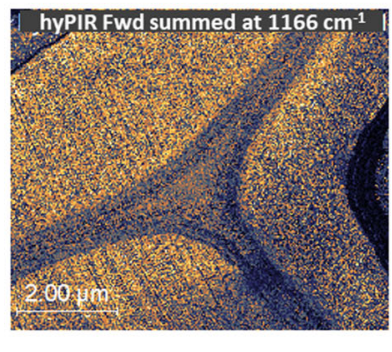

$2.31 \mathrm{mV}$

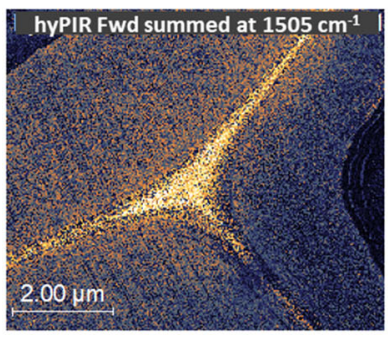

$0.11 \mathrm{mV}$

$1.43 \mathrm{mV}$

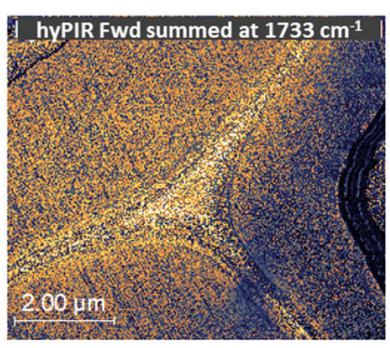

$7.48 \mathrm{mV}$

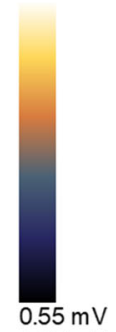

$1.07 \mathrm{mV}$

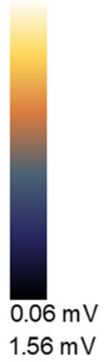

$0.05 \mathrm{mV}$ $6.33 \mathrm{mV}$

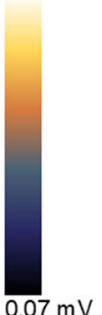

Fig. 3 Topography and hyPIR images of an ultrathin Norway spruce cross section plotted at a number of different wavenumbers from 1034 to $1733 \mathrm{~cm}^{-1}$. The images reveal the presence of several cell wall sublayers

ca. $1100 \mathrm{~cm}^{-1}$ were recognized as cellulosic bands (Agarwal and Ralph 1997; Halttunen et al. 2001; Wiley and Atalla 1987). Characteristic lignin absorption band pattern was observed at 1505, 1471 and $1451 \mathrm{~cm}^{-1}$. An ester band at $1733 \mathrm{~cm}^{-1}$ originated obviously from the acetylated galactoglucomannans that are the main type of hemicellulose in softwood species.

The cell wall layer (dark blue) next to the lumen had a spectrum that was almost identical to that of $S_{2}$ (Fig. 4). This tracheid obviously lacked the $S_{3}$ layer region. Instead, the lumen wall seemed to be covered with a substance that had a spectrum quite different from the other regions, with a strong absorption at ca. $1620 \mathrm{~cm}^{-1}$ which is typical of unsaturated structures that are present e.g. in suberin (Rocha et al. 2001).

The CCML region had strong lignin absorption bands at 1505,1471 and $1451 \mathrm{~cm}^{-1}$ similar to the lignin in the $S_{2}$ layer (Fig. 4). Moreover, additional strong absorption bands were at 1220 and $1145 \mathrm{~cm}^{-1}$, typical of condensed structures, such as dibenzodioxocin (Bock et al. 2020), that are known be present in softwood lignin. These additional absorption bands were also present in CML but not in the remaining 


\section{Topography}

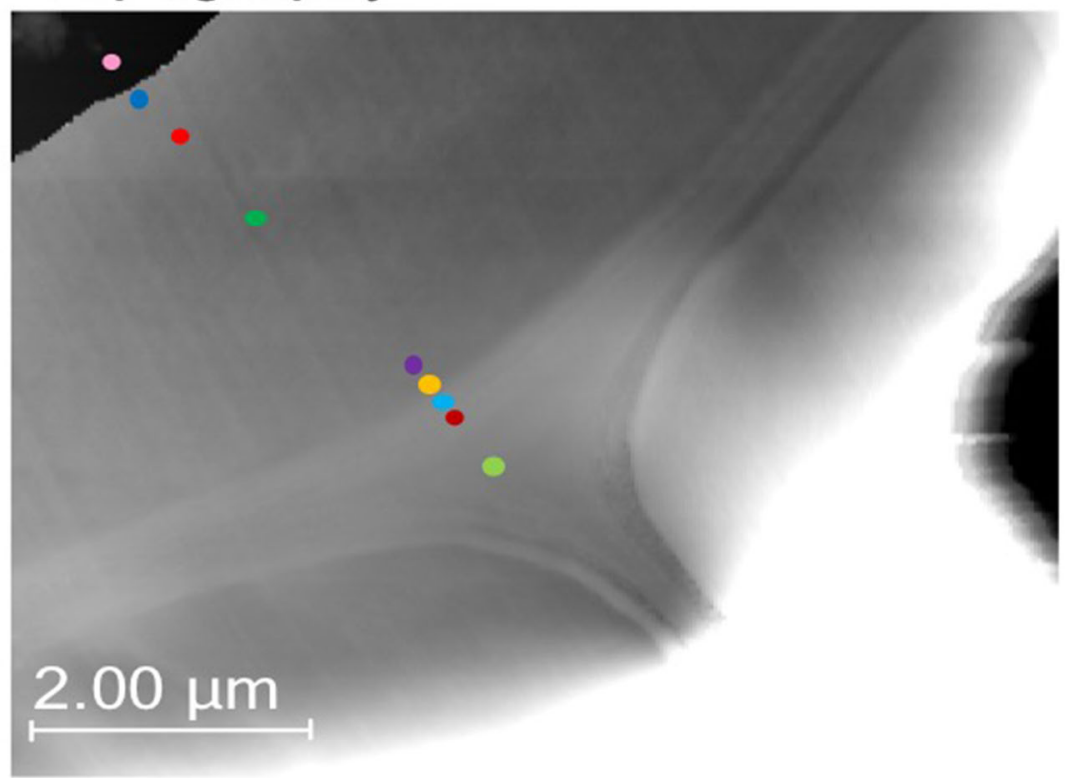

\section{$404 \mathrm{~nm}$}

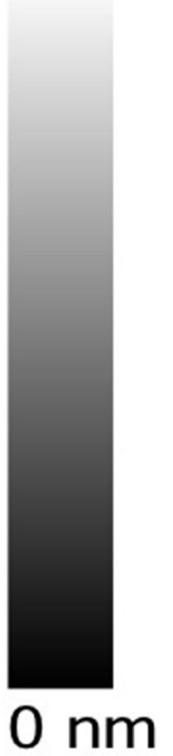

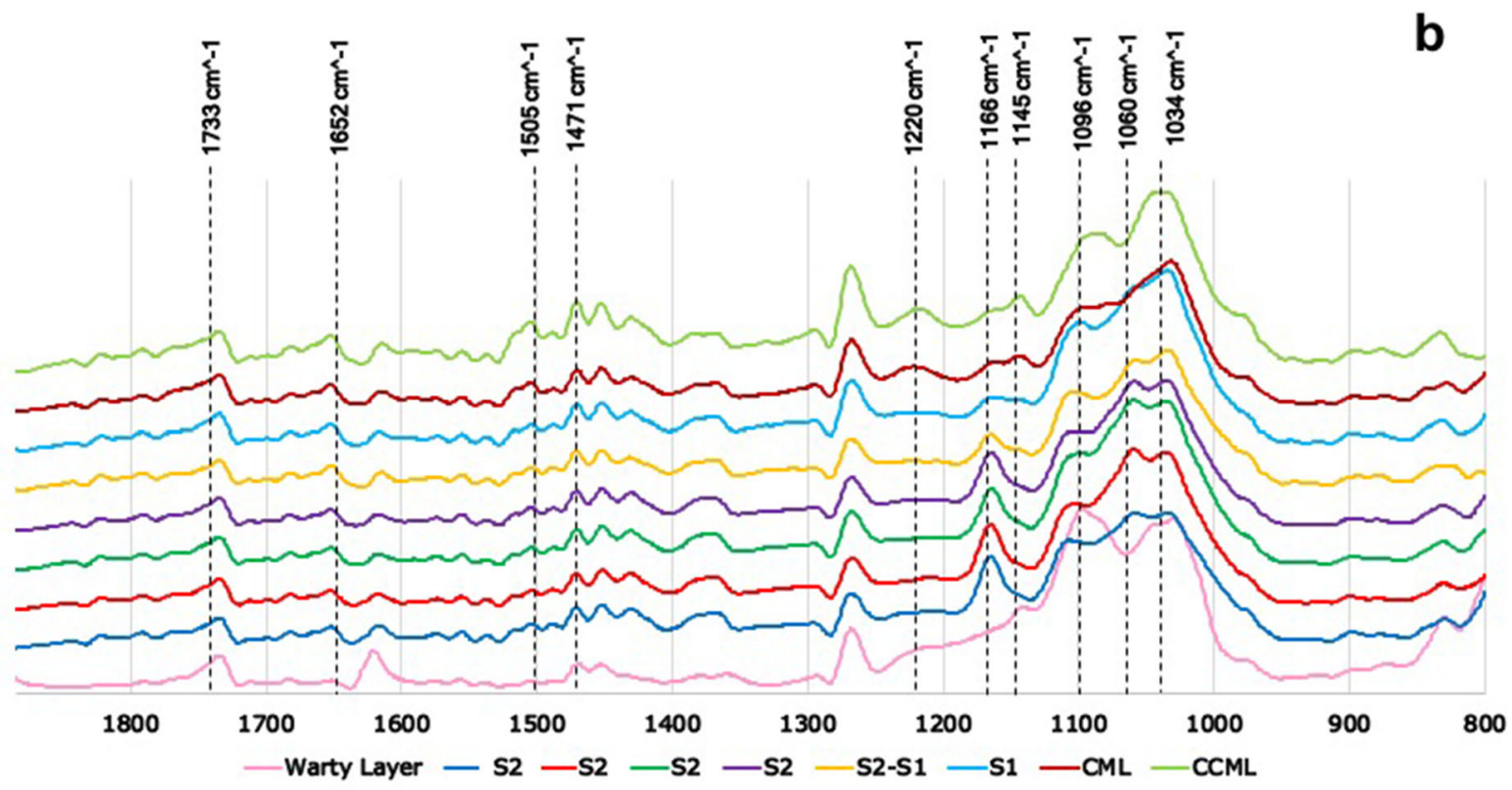

Fig. 4 a Topography image of an ultrathin Norway spruce cross section with color codes on the concentric cell wall regions. b Averaged PiFM spectra from the color-coded regions with their tentative assignments as CCML, CML, $S_{1}, S_{1-2}$ and $S_{2}$

regions of the cell wall. Earlier immunolabeling studies suggested the occurrence of lignin dibenzodioxocin structures in $\mathrm{S}_{3}$ layer of Norway spruce normal wood except for juvenile wood (Kukkola et al. 2003). Thus, the absence of condensed lignin structures in the innermost secondary wall layer obviously resulted from the young cambial age of the region.

In order to study the spectral features of the outer layers of the cell wall more precisely, a topography image and point PiFM spectra were collected with 
$15.6 \mathrm{~nm}$ resolution instead of the $30 \mathrm{~nm}$ resolution of the hyPIR images. The acquisition time was increased from $200 \mathrm{~ms}$ to $30 \mathrm{~s}$ to improve the signal-to-noise ratio. The information obtained from the point PiFM spectra mostly confirmed the observations from the hyPIR experiments: high lignin content and presence of condensed lignin structures in CCML and CML (Agarwal 2006; Burke et al. 1974; Meier 1985; Whiting and Goring 1983; Zhang et al. 2020) and axially oriented EFs in $S_{2}$ (Fig. 5). One of the point spectra, obviously part of $S_{1}$ or $S_{1-2}$, had strikingly low lignin content close to the cell corner (spectrum 7 in Fig. 5). Abnormal regions of low lignin content have been reported earlier in literature. For example, a low lignin content of $\mathrm{S}_{1-2}$ was reported earlier by many researchers who studied wood cross sections by TEM (Brändström et al. 2003; Donaldson et al. 1995; Fromm et al. 2003; Reza et al. 2014a, b; Reza et al. 2019). However, lignin-poor PiFM point spectra may result from nanoscale variation in the chemical composition instead of a region of low lignin content.

The structure of the cell wall and its sublayers varies significantly between individual tracheids, e.g. relative to $\mathrm{EF}$ orientation (Donaldson and $\mathrm{Xu} 2005$; Reza et al. 2019). Therefore, the results presented here are preliminary and mainly demonstrate the power of IR PiFM in analyzing chemical composition of the thin sublayers that are present in plant cell walls.

High resolution PiFM imaging of cell wall

PiFM imaging of the outer layers of the cell wall revealed textures and spots of variable chemical composition in small scale (Fig. 6). These features became visible when the resolution was increased first to $3.9 \mathrm{~nm}$ and then further to 1.6 and $0.6 \mathrm{~nm}$. PiFM images at $1503 \mathrm{~cm}^{-1}$ revealed the presence of spots of low lignin content in the lignin-rich $\mathrm{S}_{1}$ or CML-S region. Similarly, PiFM images collected at $1051 \mathrm{~cm}^{-1}$ showed corresponding spots of high cellulose content. The size of these features varied from few nanometers to ca. $20 \mathrm{~nm}$. The size of the smaller spots (ca. $5 \mathrm{~nm}$ ) was close to the width of individual EFs. The larger ones were as thick as the helical EF bundles that were recently shown to exist in the $\mathrm{S}_{1}$ layer of spruce cell wall (Reza et al. 2019, 2017). Several studies have also reported that $\mathrm{EF}$ bundles are present in the $\mathrm{S}_{2}$ layer (Fahlen and Salmen 2002; Singh and Daniel 2001; Xu et al. 2007).
Patterns similar to those in the PiFM images were also observed in the topography images (Fig. 6). The nanoscale height variation was only few nanometers and could possibly originate from the surface roughness of helical EF bundles.

A region of a single larger spot, tentatively assigned as part of an EF bundle, was carefully analyzed through measuring full PiFM spectra $\left(800-1800 \mathrm{~cm}^{-1}\right)$ in the middle of the spot and ca. 1 and $10 \mathrm{~nm}$ apart from it (Fig. 7). All spectra included strong bands at ca. 1050 and $1100 \mathrm{~cm}^{-1}$, which are characteristic of EFs perpendicular to the polarization plane of light (Sturcova et al. 2004). Thus, the observed spots cannot originate from axially oriented EFs, that was originally considered as a possible explanation. In contrast, the underlying tangentially oriented EFs and EF bundles, typical of $S_{1}$, may simply have non-lignified regions of this scale. Strong ester absorption (ca. $1735 \mathrm{~cm}^{-1}$ ) was found in all spectra indicating that either acetylated hemicelluloses or methyl esterified pectins were present in the spot area and outside it (Agarwal 2006; Lupoi et al. 2015; Schwanningera 2004). The interactions between EFs, their aggregates and the other cell wall polymers have been studied and discussed widely (Bardage et al. 2004; Duchesne et al. 2000; Donaldson 2007; Rongpipi et al. 2019; Salmen and Olsson 1998). An uneven distribution of ferulate ester groups of pectins and hemicelluloses, known to be nucleation sites of lignin formation, could plausibly explain the uneven lignin distribution in nanoscale. Another possibility is that the ultramicrotome sectioning leads to some random variation in the surface lignin content. However, the presence of ca. $20 \mathrm{~nm}$ wide lignin-free areas means that several EFs may entangle together without any lignin between them.

Further studies were conducted to measure the width of the non-lignified areas (Fig. 8). PiFM $\left(1503 \mathrm{~cm}^{-1}\right)$ intensity profiles were plotted in steps of $0.6 \mathrm{~nm}$ over the lignin-free spots. The half-width of the smallest spots was ca. $5 \mathrm{~nm}$, close to the size of EF that has been reported to have a hexagonal cross section of $3.2 \times 5.3 \mathrm{~nm}$ (Ding and Himmel 2006; Ding et al. 2014; Frey-Wyssling and Muhlethaler 1963; Fernandes et al. 2011). On the other hand, thinner bridging elements occur regularly between EFs (Donaldson and Singh 1998; Kerr and Goring 1975; Reza 2016). The width of the larger nonlignified areas was in the cross-section range of EF 


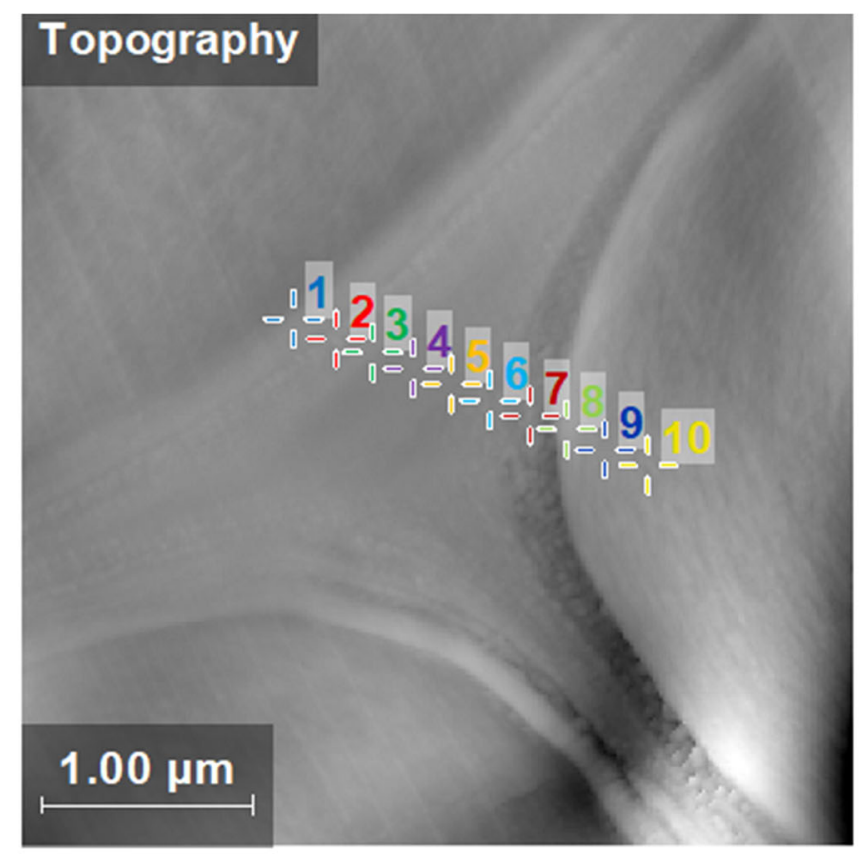

\section{$221 \mathrm{~nm}$}
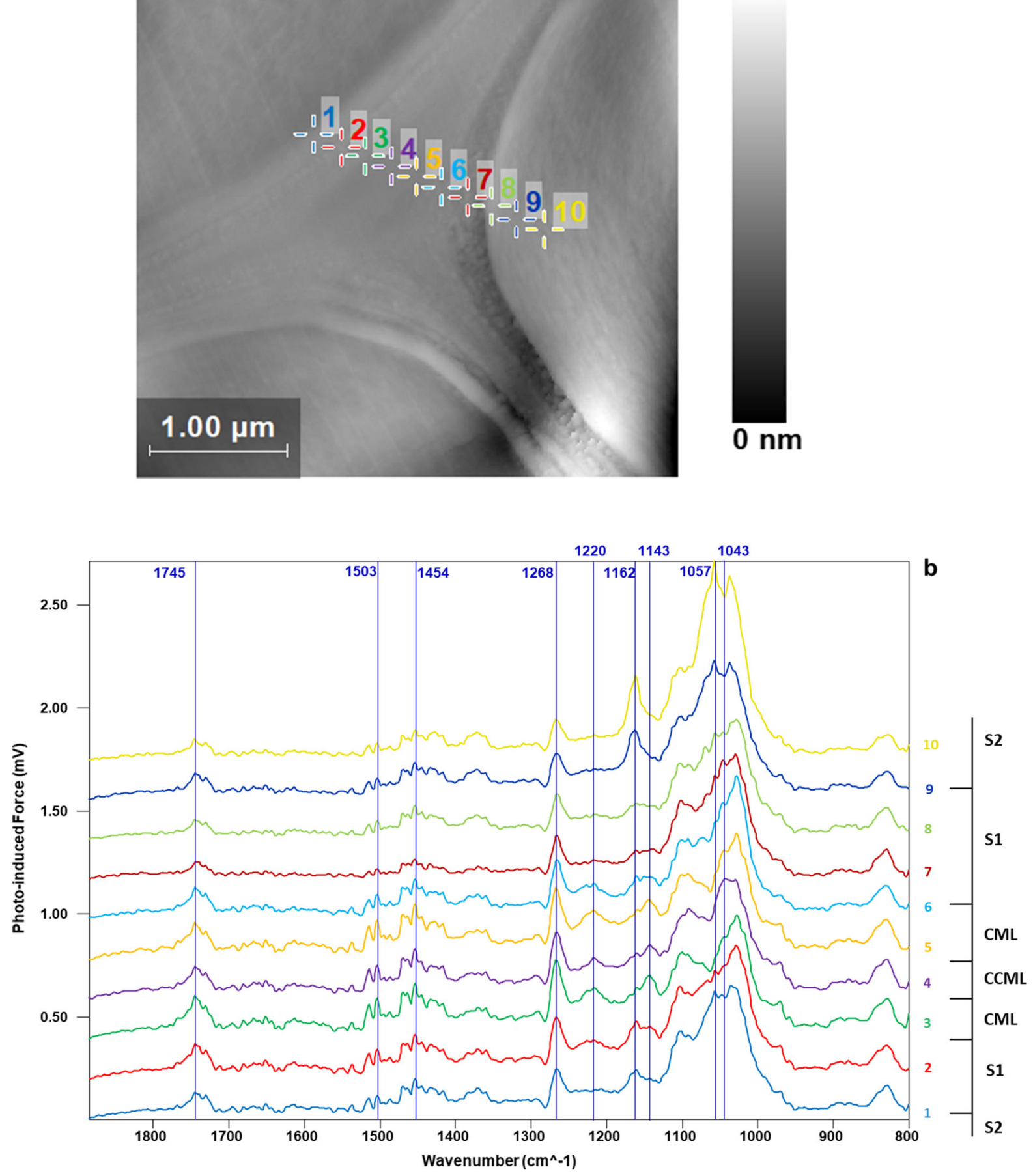

Fig. 5 a Topography image of an ultrathin Norway spruce cross section with numbered color codes for point spectra positions in different regions of the cell wall. b PiFM spectra from the colorcoded points with their tentative assignments as CCML, CML,
$S_{1}$ and $S_{2}$. Spectra 1 and 6 probably represent transition layers $\mathrm{S}_{1-2}$ and of $\mathrm{S}_{1}$-CML (Gierlinger and Schwanninger 2006), respectively 


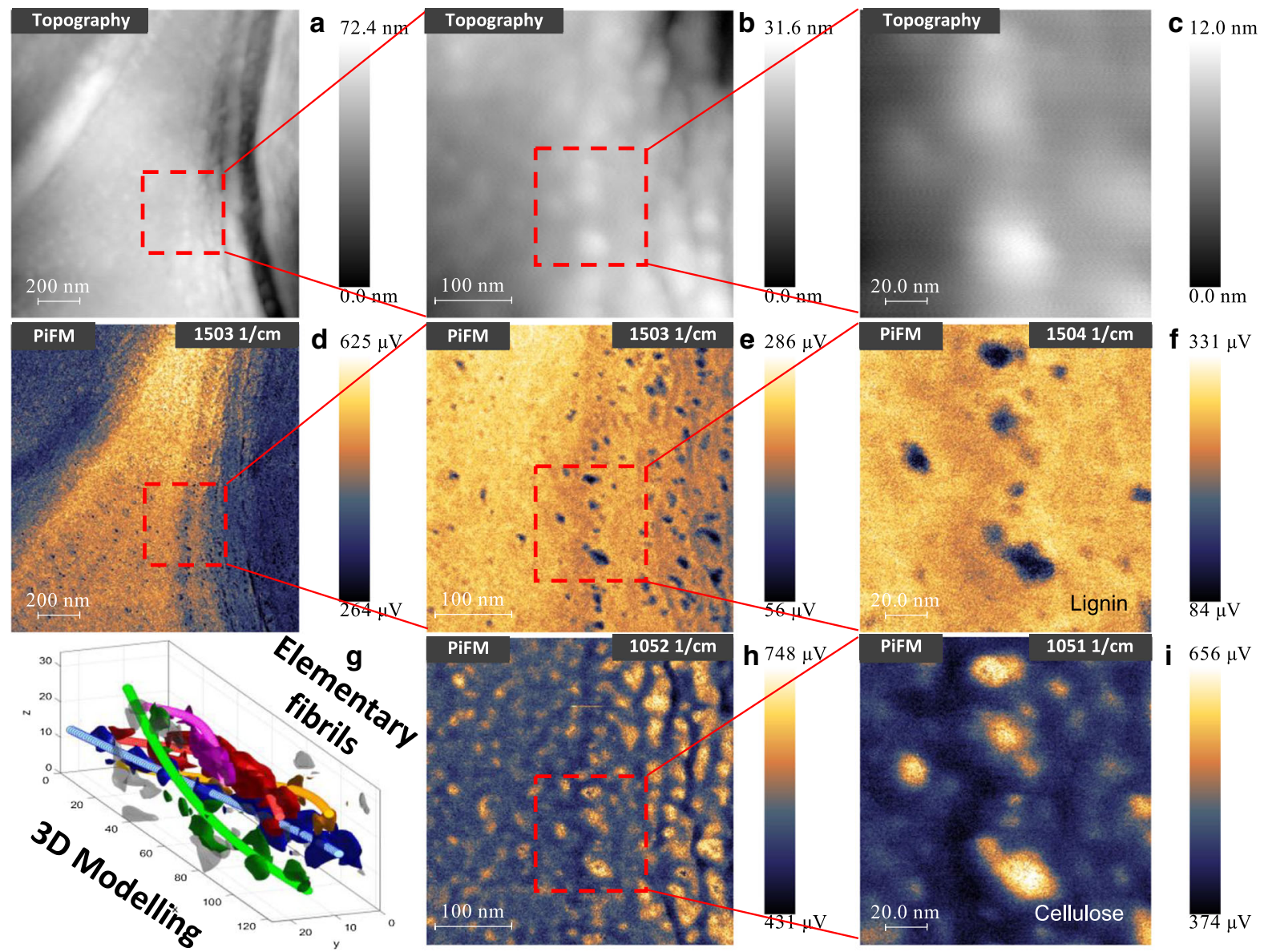

Fig. 6 Topography (a-c) and PiFM images of an ultrathin Norway spruce cross section at ca. 1503 (d-f) and 1052 (h, i) $\mathrm{cm}^{-1}$ at three different magnifications (dimensions shown by the scalebars). A TEM tomography image of a helical EF bundle

aggregates that have been investigated by several researchers (Donaldson 2007; Hodge and Wardrop 1950; Hult et al. 2001; Preston et al. 1948; Reza et al. 2014a, b). In comparison with PiFM, the topography profiles were much more difficult to analyze and they resulted in larger aggregate size values.

Assuming an abrupt change in the chemical composition between the lignified and lignin-free regions, it is possible to estimate a lower limit for the spatial resolution of the measurement and characteristics of immersion sampling technique in confocal Raman depth profiling (Vyörykkä et al. 2002). In PiFM spots 1-5 in Fig. 8 the change in intensity occurred in ca. $5 \mathrm{~nm}$ and therefore it is possible to state that the spatial resolution was $\leq 5 \mathrm{~nm}$. with its dimensions (nm) is also shown (g) (Reza et al. 2017). The vertical cellulose-rich patterns in the PiFM images at ca. $1050 \mathrm{~cm}^{-1}$ may represent tangentially organized EF bundles that are typical of $S_{1}$ layer of Norway spruce tracheids

In $\mathrm{S}_{2}$ layer small lignin-free spots were also present. Their width was ca. $5 \mathrm{~nm}$ and they often occurred at ca. $10 \mathrm{~nm}$ distance from each other (Fig. 9). These spots obviously represented cross sections of close to axially oriented EFs.

\section{Conclusion}

IR PiFM is a breakthrough in analyzing the nanoscale physical and chemical structures of plant cell walls. In comparison with the commonly used chemical imaging by Raman microscopy, IR PiFM can reach $\geq 50$ times higher spatial resolution. The resolution is also several times higher than what has been reported for thermal expansion AFM-IR (Gusenbauer et al. 2020). 

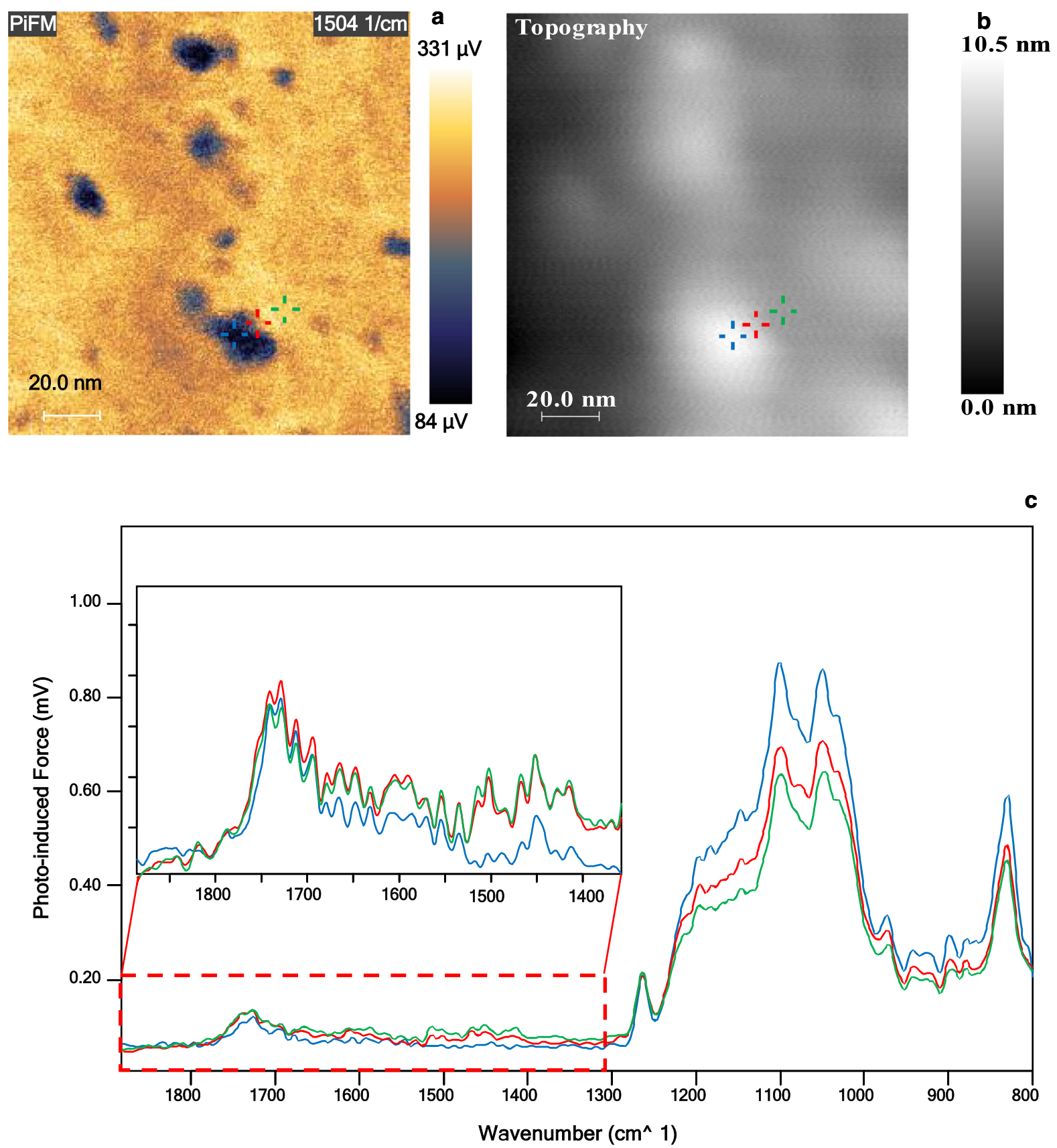

Fig. 7 PiFM point spectra taken from the locations shown by the color codes in the high resolution PiFM and tomography images of an ultrathin cross section of Norway spruce

The ultimate resolution of IR PiFM depends on the tip and the photoinduced effect between the tip and the sample. The technique is also surface sensitive (ca. $10 \mathrm{~nm}$ analysis depth), which makes the analysis more straightforward in comparison with TEM that images typically $100-200 \mathrm{~nm}$ sections over their whole thickness. IR PiFM requires no sample pretreatment other than cutting high-quality microtome sections of the sample. The high spatial resolution in combination with the chemical resolution makes IR PiFM competitive with TEM also in structural analysis of the cell wall. Unlike IR PiFM, TEM requires staining for 

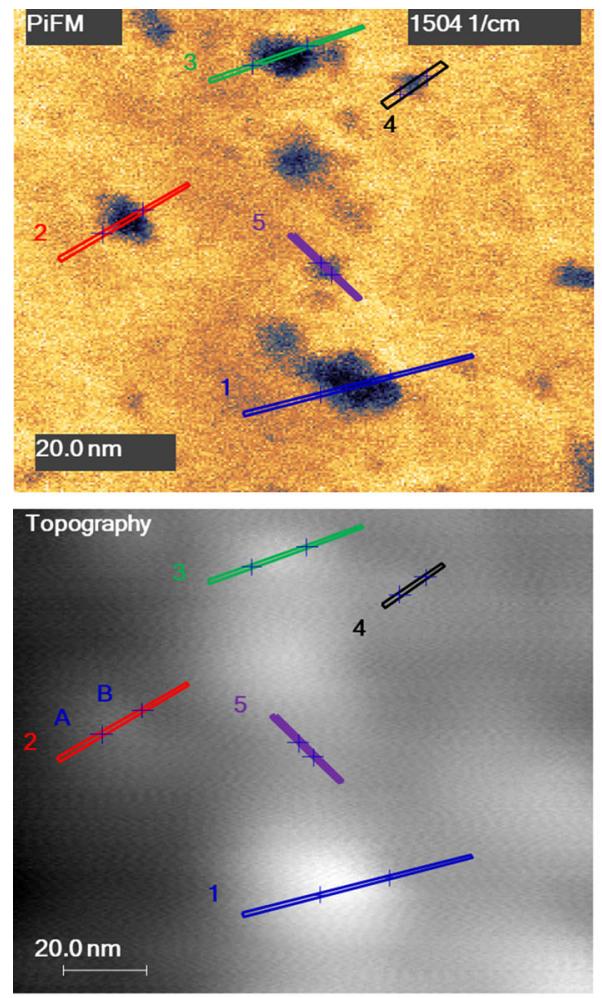

Topography
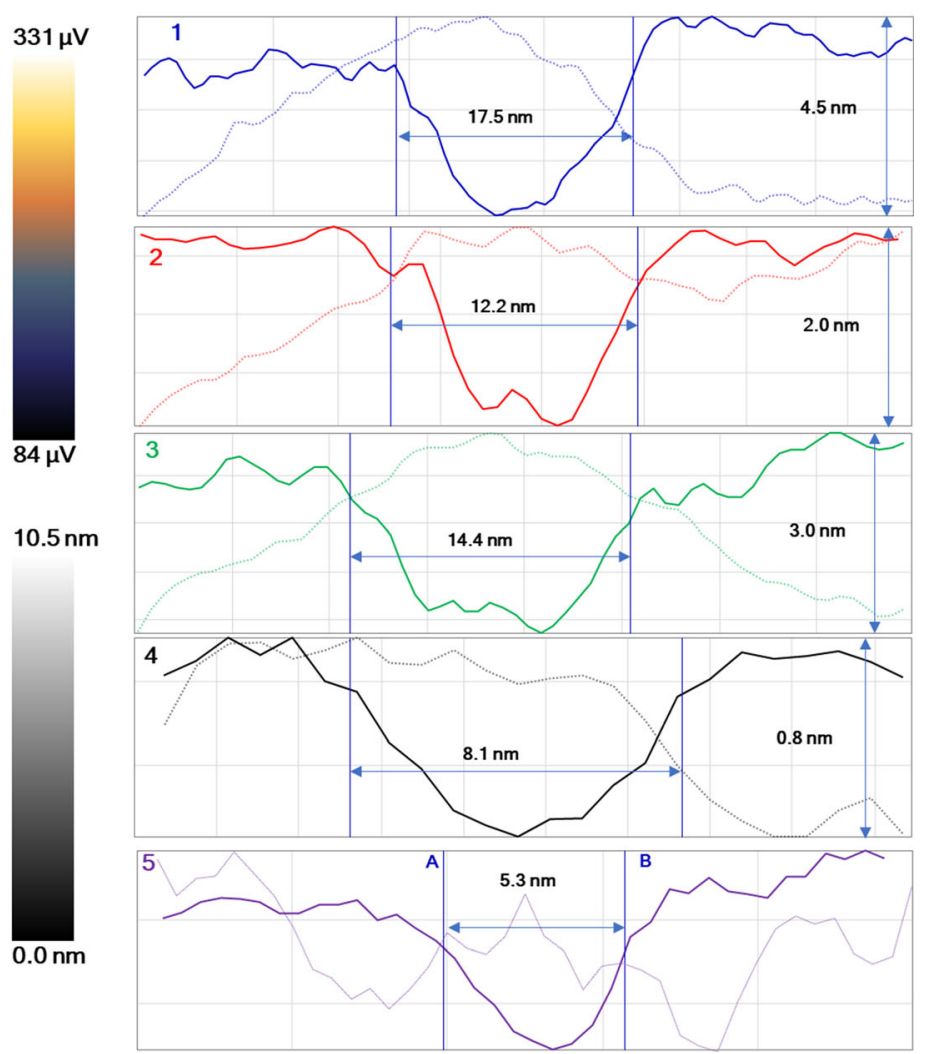

Fig. 8 Topography (dashed line) and PiFM $\left(1504 \mathrm{~cm}^{-1}\right.$, solid line) intensity profiles (right) along the color-coded lines in highresolution topography and PiFM images (left) of an ultrathin section of Norway spruce
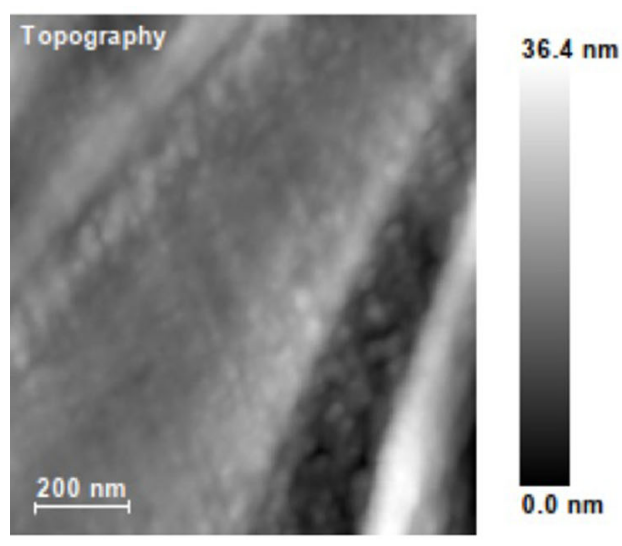

Fig. 9 Topography and PiFM (at $1503 \mathrm{~cm}^{-1}$ ) images of an ultrathin Norway spruce cross section. $S_{2}$ regions in the top left and downright regions lack the large lignin-free spots typical of

contrast enhancement which may alter the original structure.

IR PiFM of Norway spruce cross sections confirmed the presence of lignin-free EF aggregates in the

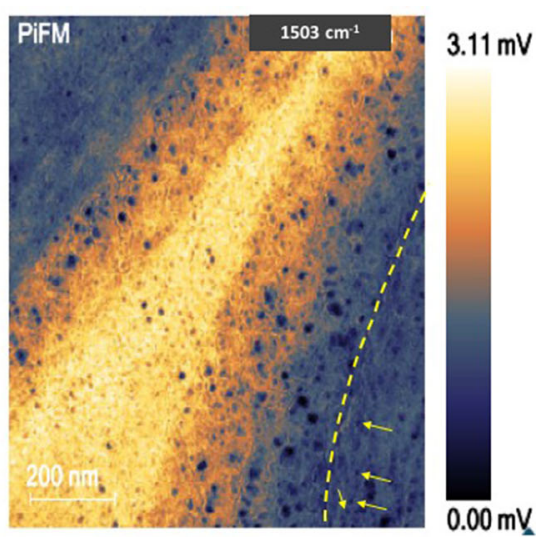

the outer cell wall layers. Instead, ca. $5 \mathrm{~nm}$ wide lignin-free spots at ca. $10 \mathrm{~nm}$ distance from each other are characteristic of $\mathrm{S}_{2}$ layer

outer cell wall while individual EFs (true width 3-4 nm, observed width 5-6 nm) were more typical for the $S_{2}$ layer. The presence of both EF aggregates and lignin affect the accessibility and reactivity of 
cellulose and contribute to the recalcitrance of biomass in fractionating and converting it into various products (dos Santos 2013; Michelin et al. 2020; Reza et al. 2017). In the future, IR PiFM could be applied for analyzing the detailed chemical and physical structure of different biomass sources and getting better understanding on their reactivity and suitability in various applications in the fields of material science, life sciences, biofuel production, etc.

Acknowledgments The PiFM and hyPIR images were carried out by Molecular Vista Inc. (San Jose, CA, USA), in partnership with Anfatec Instruments AG (Oelsnitz, Germany). We thank Mr. Raimon Zoetemelk (ST Instruments, The Netherlands) for his help in initiating the research. This research work used additionally premises of Aalto University Nanomicroscopy Center (Aalto-NMC).

Funding Open access funding provided by Aalto University. We thankfully acknowledge the Academy of Finland (grant number 290324) for financial support.

Data availability All the given data in this manuscript that supports the findings are available from the corresponding authors.

\section{Declarations}

Conflict of interest The author(s) declare no competing interests, or other interests that might be perceived to influence the results and/or discussion reported in this paper.

Consent for publication All authors have read and approved the final version of manuscript for publication.

Open Access This article is licensed under a Creative Commons Attribution 4.0 International License, which permits use, sharing, adaptation, distribution and reproduction in any medium or format, as long as you give appropriate credit to the original author(s) and the source, provide a link to the Creative Commons licence, and indicate if changes were made. The images or other third party material in this article are included in the article's Creative Commons licence, unless indicated otherwise in a credit line to the material. If material is not included in the article's Creative Commons licence and your intended use is not permitted by statutory regulation or exceeds the permitted use, you will need to obtain permission directly from the copyright holder. To view a copy of this licence, visit http://creativecommons.org/licenses/by/4.0/.

\section{References}

Abe H, Funada R (2005) Review-the orientation of cellulose microfibrils in the cell walls of tracheids in conifers. IAWA J 26:161-174
Abe H, Ohtani J, Fukazawa K (1991) FE-SEM observation on the microfibrillar orientation in the secondary wall of tracheids. IAWA J 12:431-438

Abe H, Ohtani J, Fukazawa K (1992) Microfibrillar orientation of the innermost surface of conlfer tracheid walls. IAWA Bull N S 13:411-438

Agarwal UP (2006) Raman imaging to investigate ultrastructure and composition of plant cell walls: distribution of lignin and cellulose in black spruce wood (Picea mariana). Planta 224:1141-1153

Agarwal UP, Ralph SA (1997) FT-Raman spectroscopy of wood: identifying contributions of lignin and carbohydrate polymers in the spectrum of black spruce (Picea mariana). Appl Spectrosc 51:1648-1655

Bardage S, Donaldson L, Tokoh C, Daniel G (2004) Ultrastructure of the cell wall of unbeaten Norway spruce pulp fibre surfaces. Nordic Pulp Paper Res J 19:448-452

Bock P, Nousiainen P, Elder T et al (2020) Infrared and Raman spectra of lignin substructures: dibenzodioxocin. J Raman Spectrosc 51:422-431

Bonnin E, Garnier C, Ralet M (2014) Pectin-modifying enzymes and pectin-derived materials: applications and impacts. Appl Microbiol Biotechnol 98:519-532

Brändström J, Bardage SL, Daniel G, Nilsson T (2003) The structural organisation of the S1 cell wall layer of norway spruce tracheids. IAWA J 24:27-40

Burke D, Kaufman P, McNeil M, Albersheim P (1974) The structure of plant cell walls: VI. A survey of the walls of suspension-cultured monocots. Plant Physiol 54:109-115

Charrier AM, Lereu AL, Farahi RH, Davison BH, Passian A (2018) Nanometrology of biomass for bioenergy: the role of atomic force microscopy and spectroscopy in plant cell characterization. Front Energy Res 6(11):1-9

Chundawat SPS, Beckham GT, Himmel ME, Dale BE (2011) Deconstruction of lignocellulosic biomass to fuels and chemicals. Annu Rev Chem Biomol Eng 2:121-145

Ding SY, Himmel ME (2006) The maize primary cell wall microfibril: a new model derived from direct visualization. J Agric Food Chem 54:597-606

Ding SY, Zhao S, Zeng Y (2014) Size, shape, and arrangement of native cellulose fibrils in maize cell walls. Cellulose 21:863-871

Donaldson LA (1995) Cell wall fracture properties in relation to lignin distribution and cell dimensions among three genetic groups of radiate pine. Wood Sci Technol 29:51-63

Donaldson LA (2007) Cellulose microfibril aggregates and their size variation with cell wall type. Wood Sci Technol 41:443-460

Donaldson L (2008) Microfibril angle: measurement, variation and relationships: a review. IAWAJ 29(4):345-386

Donaldson LA, Singh AP (1998) Bridge-like structure between cellulose microfibrils in radiata pine (Pinus radiata D.Don) kraft pulp and holocellulose. Holzforschung 52:449-454

Donaldson L, Xu P (2005) Microfibril orientation across the secondary cell wall of Radiata pine tracheids. Trees 19:644-653

dos Santos NM. Influence of chemical and enzymatic treatments on a variety of wood pulps on their dissolution in $\mathrm{NaOH}$ water. In chapter 1- "State of the art review on wood cell wall structure, cellulose reactivity and dissolution" Other. 
Ecole Nationale Supérieure des Mines de Paris, 2013. English. NNT: 2013ENMP0070. pastel-00978915

Dou J, Kim H, Li Y, Padmakshan D, Yue F, Ralph J, Vuorinen T (2018) Structural characterization of Lignins from Willow Bark and wood. J Agricul Food Chem 66(28):7294-7300

Duchesne I, Daniel G (2000) Changes in surface ultrastructure of Norway spruce fibres during kraft pulping - visualisation by field emission-SEM. Nordic Pulp Paper Res J 15:054-061

Fahlén J, Salmén L (2002) On the Lamellar structure of the tracheid cell wall. Plant Biol 4:339-345

Fernandes AN, Thomas LH, Altaner CM, Callow P, Forsyth VT, Apperley DC, Kennedy CJ, Jarvis MC (2011) Nanostructure of cellulose microfibrils in spruce wood. Proc Natl Acad Sci 108:E1195-E1203

Frey-Wyssling VA, Mühlethaler K (1963) Die elementarfibrillen der cellulose. Die Makromolekulare Chemie 62:25-30

Fromm J, Rockel B, Lautner S, Windeisen E, Wanner G (2003) Lignin distribution in wood cell walls determined by TEM and backscattered SEM techniques. J Struct Biol 143:77-84

Gierlinger N, Schwanninger M (2006) Chemical imaging of poplar wood cell walls by confocal Raman microscopy. Plant Physiology Apr 140(4):1246-1254

Gierlinger N, Luss S, König C, Konnerth J, Eder M, Fratzl P (2010) Cellulose microfibril orientation of Picea abies and its variability at the micron-level determined by Raman imaging. J Experimen Botany 61(2):587-595

Gusenbauer C, Jakob DS, Xu XG, Vezenov DV, Cabane É, Konnerth J (2020) Nanoscale chemical features of the natural fibrous material wood. Biomacromol 21(10):4244-4252

Halttunen M, Vyörykkä J, Hortling B et al (2001) Study of residual Lignin in pulp by UV resonance Raman spectroscopy. Holzforschung 55:631-638

Hänninen T, Kontturi E, Vuorinen T (2011) Distribution of lignin and its coniferyl alcohol and coniferyl aldehyde groups in Picea abies and Pinus sylvestris as observed by Raman imaging. Phytochemistry 72(14-15):1889-1895

Hodge AJ, Wardrop AB (1950) An electron-microscopic investigation of the cell-wall organisation of conifer tracheids. Nature 165:272-273

Huang CL, Lindstrom H, Nakada R, Ralston J (2003) Cell wall structure and wood properties determined by acoustics-a selective review. Holz Als Roh- Und Werkstoff 61:321-335

Hult EL, Larsson PT, Iversen T (2001) Cellulose aggregationan inherent property of Kraft pulps. Polymer 42:3309-3314

Ibn YA, Edlund U, Albertsson AC (2017) Transfer of Biomatrix/Wood cell interactions to hemicellulose-based materials to control water interaction. Chem Rev 117(12):8177-8207

Jingjing L (2011) Isolation of lignin from wood. Saimaa University of Applied Sciences, Imatra, Thesis, pp 1-57

Johansson M (2000) Formation of Chromophores and Leucochromophores during Manufacturing of Mechanical Pulp. Licentiate Thesis, Royal Institute of Technology, Stockholm, Sweden

Kerr AJ, Goring DAI (1975) Ultrastructural arrangement of the wood cell wall. Cellulose Chem Technol 9:563-573
Kesari KK, Leppänen M, Ceccherini S, Seitsonen J, Väisänen S, Altgen M, Johansson LS, Maloney T, Ruokolainen J, Vuorinen T (2020) Chemical characterization and ultrastructure study of pulp fibers. Mater Today Chem 17:100324

Kukkola EM, Koutaniemi S, Gustafsson M et al (2003) Localization of dibenzodioxocin substructures in lignifying Norway spruce xylem by transmission electron microscopy-immunogold labeling. Planta 217:229-237

Larsen KL, Barsberg S (2010) Theoretical and Raman spectroscopic studies of phenolic lignin model monomers. J Phys Chem B 114:8009-8021

Levin IW, Bhargava R (2005) Fourier transform infrared vibrational spectroscopic imaging: integrating microscopy and molecular recognition. Annu Rev Phys Chem 56:429-474

Lewis EN, Treado PJ, Reeder RC, Story GM, Dowrey AE, Marcott C, Levin IW (1995) Fourier transform spectroscopic imaging using an infrared focal-plane array detector. Anal Chem 67:3377-3381

Lin SY, Kringstad KP (1970a) Photosensitive groups in lignin and lignin model compounds. Tappi 53(4):658-663

Lin SY, Kringstad KP (1970b) Stabilization of Lignin and Lignin model compounds to photodegredation. Tappi 53(9):1675-1677

Lupoi JS, Gjersing E, Davis MF (2015) Evaluating lignocellulosic biomass, its derivatives, and downstream products with Raman spectroscopy. Front Bioeng Biotech 3(50):2

Lyczakowski JJ, Bourdon M, Terrett OM, Helariutta Y, Wightman R, Dupree P (2019) Structural imaging of native cryo-preserved secondary cell walls reveals the presence of Macrofibrils and their formation requires normal cellulose, Lignin and Xylan Biosynthesis. Front Plant Sci 10:1398

Maaß MC, Saleh S, Militz H, Volkert CA (2020) The structural origins of wood cell wall toughness. Adv Mater 32:1907693

Meier H (1985) Localization of polysaccharides in wood cell walls. In: Higuchi T (ed) Biosynthesis and biodegradation of wood components. Academic, Orlando, Florida, pp 43-50

Melelli A, Arnould O, Beaugrand J, Bourmaud A (2020) The middle Lamella of plant fibers used as composite reinforcement: investigation by atomic force microscopy. Molecules 25:632

Michelin M, Gomes DG, Romaní A, Polizeli MdLTM, Teixeira JA (2020) Nanocellulose production: exploring the enzymatic route and residues of pulp and paper industry. Molecules 25:3411

Murdick R, Morrison W, Nowak D, Albrecht TR, Jahng J, Park S (2017) Photoinduced force microscopy: a technique for hyperspectral nanochemical mapping. Japanese J Appl Phy 56: 08LA04

Nguyen-Tri P, Ghassemi P, Carriere P, Nanda S, Assadi AA, Nguyen DD (2020) Recent applications of advanced atomic force microscopy in polymer science: a review. Polymers 12:1142

Nowak D, Morrison W, Wickramasinghe HK, Jahng J, Potma EO, Wan L, Ruiz R, Albrecht TR, Schmidt K, Frommer J, Sanders DP, Park S (2016) Nanoscale chemical imaging by photoinduced force microscopy. Sci Adv 2:e1501571e1501571 
Ogunleke A, Bobroff V, Chen H, Rowlette J, Delugin M, Recur B, Hwu Y, Petibois C (2017) Fourier-transform vs. quantum-cascade-laser infrared microscopes for histo-pathology: from lab to hospital? Trac-Trends Analytical Chem 89:190-196

Pereira L, Flores-Borges DNA, Bittencourt PRL, Mayer JLS, Kiyota E, Araújo P, Jansen S, Freitas RO, Oliveira RS, Mazzafera P (2018) Infrared nanospectroscopy reveals the chemical nature of pit membranes in water-conducting cells of the plant Xylem. Plant Physiol 177(4):1629-1638

Plaza NZ, Pingali SV, Qian S, Heller WT, Jakes JE (2016) Informing the improvement of forest products durability using small angle neutron scattering. Cellulose 23:1593-1607

Preston RD, Nicolai E, Reed R, Millard A (1948) An electron microscope study of cellulose in the wall of Valonia ventricosa. Nature 162:665-667

Reza MM (2016) Study of Norway spruce cell wall structure with microscopy tools. Aalto University. http://urn.fi/ URN:ISBN:978-952-60-6684-4

Reza M, Rojas LG, Kontturi E, Vuorinen T, Ruokolainen J (2014a) Accessibility of cell wall lignin in solvent extraction of ultrathin spruce wood sections. ACS Sustain Chem Eng 2(4):804-808

Reza M, Ruokolainen J, Vuorinen T (2014b) Out-of-plane orientation of cellulose elementary fibrils on spruce tracheid wall based on imaging with high-resolution transmission electron microscopy. Planta 240:565-573

Reza M, Kontturi E, Jääskeläinen AS, Vuorinen T, Ruokolainen J (2015) Transmission electron microscopy for wood and fiber analysis: a review. BioResources 10(3):6230-6261

Reza M, Bertinetto C, Ruokolainen J, Vuorinen T (2017) Cellulose elementary fibrils assemble into helical bundles in $\mathrm{s}_{1}$ layer of Spruce Tracheid Wall. Biomacromol 18(2):374-378

Reza M, Bertinetto C, Kesari KK, Engelhardt P, Ruokolainen J, Vuorinen T (2019) Cellulose elementary fibril orientation in the spruce $S_{1-2}$ transition layer. Sci Rep 9(1):3869

Rocha SM, Goodfellow BJ, Delgadillo I, Neto CP, Gil AM (2001) Enzymatic isolation and structural characterisation of polymeric suberin of cork from Quercus suber L. Int J Biol Macromol 28(2):107-119

Rongpipi S, Ye D, Gomez ED, Gomez EW (2019) Progress and opportunities in the characterization of cellulose: an important regulator of cell wall growth and mechanics. Front Plant Sci 9:1894

Salmén L, Olsson A (1998) Interactions between hemicelluloses, lignin and cellulose; structure property relationships. J Pulp Pap Sci 24:99-103

Schulz H, Baranska M (2007) Identification and quantification of valuable plant substances by IR and Raman spectroscopy. Vib Spectrosc 43:13-25

Schwanningera M, Rodriguesc JC, Pereirac H, Hinterstoisser B (2004) Effects of short-time vibratory ball milling on the shape of FT-IR spectra of wood and cellulose. Vib Spectrosc 36:23-40

Singh AP, Daniel G (2001) The S2 layer in the Tracheid Walls of Picea abies wood: inhomogeneity in Lignin distribution and cell wall microstructure. Holzforschung 55:373-378

Sorieul M, Dickson A, Hill SJ, Pearson H (2016) Plant fibre: molecular structure and biomechanical properties, of a complex living material, influencing its deconstruction towards a biobased composite. Materials (basel) 9(8):618

Stefke B, Windeisen E, Schwanninger M, Hinterstoisser B (2008) Determination of the weight percentage gain and of the acetyl group content of acetylated wood by means of different infrared spectroscopic methods. Anal Chem 80(4):1272-1279

Stevanic SJ (2011) Interactions between Wood Polymers in Wood Cell Walls and Cellulose/Hemicellulose Biocomposites. $\mathrm{PhD}$ thesis

Stevanic JS, Salmen L (2009) Orientation of the wood polymers in the cell wall of spruce wood fibres. Holzforschung 63(5):497-503

Sturcova A, His I, Apperley DC, Sugiyama J, Jarvis MC (2004) Structural details of crystalline cellulose from higher plants. Biomacromol 5:1333-1339

Vyörykkä J, Halttunen M, Iitti H, Tenhunen J, Vuorinen T, Stenius P (2002) Characteristics of immersion sampling technique in confocal Raman depth profiling. Appl Spectrosc 56(6):776-782

Wang X, Deng Y, Li Y, Kjoller K, Roy A, Wang S (2016) In situ identification of the molecular-scale interactions of phenolformaldehyde resin and wood cell walls using infrared nanospectroscopy. RSC Adv 6:76318-76324

Whiting P, Goring DAI (1983) The composition of carbohydrates in the middle lamella and secondary wall of tracheids from black spruce wood. Can J Chem 61:506-508

Wiedenhoeft AC (2013) Structure and function of wood. In: Rowell RM (ed) Handbook of wood chemistry and wood composites, 2nd edn. CRC Press, Boca Raton, pp 9-32

Wiley JH, Atalla RH (1987) Band assignments in the Raman spectra of celluloses. Carbohydr Res 160:113-129

Xiao L, Schultz ZD (2018) Spectroscopic imaging at the nanoscale: technologies and recent applications. Anal Chem 90(1):440-458

Xu P, Donaldson LA, Gergely ZR, Staehelin LA (2007) Dualaxis electron tomography: a new approach for investigating the spatial organization of wood cellulose microfibrils. Wood Sci Technol 41:101-116

Zhang C, Xu LH, Ma CY, Wang HM, Zhao YY, Wu YY, Wen JL (2020) Understanding the structural changes of lignin macromolecules from Balsa wood at different growth stages. Front Energy Res 8:181

Publisher's Note Springer Nature remains neutral with regard to jurisdictional claims in published maps and institutional affiliations. 